\title{
Pengenalan Open Journal System (OJS) untuk Publikasi Ilmiah Mahasiswa
}

\author{
Elly Astuti ${ }^{1}$, Isharijadi ${ }^{2}$ \\ 1,2 Universitas PGRI Madiun
}

\begin{tabular}{|c|c|}
\hline Article History & ABSTRACT \\
\hline $\begin{array}{l}\text { Received } 10.08 .2019 \\
\text { Received in revised form } \\
\text { 17.10.2019 } \\
\text { Accepted 03.12.2019 } \\
\text { Available online 16.12.2019 }\end{array}$ & $\begin{array}{l}\text { INTRODUCTION OF OPEN JOURNAL SYSTEM FOR SCIENTIFIC } \\
\text { PUBLICATION OF STUDENTS. This activity is intended to provide } \\
\text { understanding for students that according to the latest regulations, students are } \\
\text { required to conduct scientific publications. Scientific publications are intended to } \\
\text { communicate the results of academic research carried out to contribute to the } \\
\text { development of science. However, many students do not understand how to } \\
\text { publish their work properly. This training provides material on the ethics of } \\
\text { scientific publications and how to submit articles in scientific journals. Students } \\
\text { are introduced to ways to find accredited journals in accordance with the field of } \\
\text { study. This is done to avoid student publications in predatory journals. As a result } \\
\text { of this activity, students understand the business processes of journals for the } \\
\text { scientific publication of their work. They also learned that each journal had its } \\
\text { own unique style of environment so they had to pay close attention to the author's } \\
\text { guidelines. }\end{array}$ \\
\hline
\end{tabular}

KEYWORDS: Academic Ethics, Open Journal System, Scientific Publications.

\begin{abstract}
DOI: $10.30653 / 002.201944 .189$ (C) This is an open access article distributed under the terms of the Creative Commons Attribution 4.0 International License, which permits unrestricted use, distribution, and reproduction in any medium, provided the original work is properly cited. (c) 2019 Elly Astuti, Isharijadi.
\end{abstract}

\section{PENDAHULUAN}

Publikasi ilmiah merupakan salah satu syarat wajib untuk menempuh jenjang pendidikan tinggi (sarjana, magister maupun program doktor) sesuai dengan surat edaran Kemenristek DIKTI No B/323/B.B1/SE/2019. Mahasiswa yang telah selesai menempuh program pendidikan diwajibkan untuk mengunggah hasil karya tugas akhir mereka di repository kampus ataupun jurnal ilmiah dengan indeksasi yang dipersyaratkan. Dampak dari kebijakan tersebut, mahasiswa harus mengenal media publikasi karya ilmiah mereka agar terhindar dari jurnal predator sehingga karya tersebut dapat diakui sebagai syarat kelulusan.

\footnotetext{
${ }^{1}$ Corresponding author: Program Studi Pendidikan Akuntansi, Universitas PGRI Madiun; Jl. Setia Budi No. 85 Kota Madiun, Jawa Timur,
} Indonesia. Email: ellyastuti@unipma.ac.id 
Jurnal predator merupakan jurnal palsu yang mempublikasikan karya ilmiah dengan menarik sejumlah biaya tertentu dengan janji segera terbit tanpa revisi dan kurang memenuhi kaidah integritas akademik. Jurnal predator mengeksploitasi penulis dengan cara yang kurang beretika. Keberadaan jurnal-jurnal predator sangat meresahkan pada lingkungan akademisi, untuk itu dalam proses submisi awal diperlukan pendampingan. Banyak mahasiswa utamanya di kalangan S1 yang belum memahami bagaimana mempublikasikan karyanya dengan baik dan benar. Untuk itu diperlukan suatu pelatihan terintegrasi untuk memperkenalkan bagaimana cara mencari jurnal ilmiah bukan predator dalam proses publikasi karya ilmiah mereka.

Open Journal System (OJS) merupakan suatu manajemen jurnal online berbasis web yang dikembangkan oleh PKP (Shiddieq, Purwanto, \& Santoso, 2018). OJS memudahkan pengelolaan penerbitan jurnal secara online mulai dari penerimaan naskah dari penulis, distribusi naskah, pemeriksaan naskah, penyuntingan naskah hingga penerbitan jurnal (Mauko, Setiohardjo, \& Noach, 2017). Banyak perguruan tinggi di Indonesia yang sudah mengelola penerbitan jurnal ilmiah berbasis OJS. OJS merupakan suatu sarana bagi institusi untuk mempublikasikan hasil karya civitas akademikanya agar dapat dikenal di lingkungan nasional maupun global (Yunus, Abadi, Bhuana, \& Djalal, 2018).

Pelatihan ini dilaksanakan untuk membimbing mahasiswa dalam pemilihan jurnal sebagai sarana publikasi karyanya sebagai syarat kelulusan. Kewajiban publikasi bagi mahasiswa sangat penting untuk mencegah pelanggaran integritas akademik. Ristek DIKTI juga telah meyediakan platform untuk mengunggah karya ilmiah mahasiswa Rama Repository yang terintegrasi dengan Repositori kampus. Anjani juga telah hadir untuk meningkatkan kepatuhan dalam menjaga integritas akademik. Dengan hadirnya kedua website tersebut, hasil karya mahasiswa tidak hanya berakhir di rak buku perpustakaan namun dapat diakses diseluruh dunia.

Perlahan tetapi pasti kewajiban publikasi ilmiah juga meningkatkan kualitas penelitian dan publikasi pada civitas akademika seluruh negeri. Irawan et al., (2018) menyatakan bahwa berdasarkan penelusuran terdapat 51.000 artikel yang dipublikasikan dalam bahasa indonseia sejak tahun 1984 sampai 2017. Jika dihitung rata-rata 1500 artikel pertahun, hal ini membuktikan tingginya kebutuhan jurnal yang berkualitas untuk keperluan publikasi hasil karya akademik. Untuk itu perlu adanya kewaspadaan dalam proses memilih jurnal yang baik.

\section{METODE PELAKSANAAN}

Publikasi ilmiah merupakan sebuah proses komunikasi dalam lingkungan akademik untuk menyebarkan hasil penelitiannya sebagai wujud kontribusi pengembangan ilmu pengetahuan (Fatmawati, 2013; Kristina, 2018). Publikasi karya ilmiah mahasiswa menjadi sebuah kewajiban sesuai Surat Edaran Kemenristek DIKTI No. B/323/B.B1/SE/2019. Untuk itu dilakukan pembentukan pemahaman kepada mahasiswa akan substansi pentingnya publikasi ilmiah. Kegiatan ini dimulai dengan pemaparan etika publikasi karya ilmiah berbasis online. Setelah mahasiswa memiliki pengetahuan dan pemahaman yang cukup tentang materi pendahuluan tersebut, dilanjutkan dengan materi inti pengenalan Open Journal System.

Pelatihan pengenalan Open Journal System dilakukan dengan menggunakan website prosiding FIPA (Forum Ilmiah pendidikan Akuntansi) yang dimiliki oleh Prodi 
Pendidikan Akuntansi Universitas PGRI Madiun. Mahasiswa diperkenalkan pada fiturfitur yang dimiliki oleh OJS dari perspektif pembaca dan penulis artikel.

Pelatihan dilakukan dengan demonstrasi secara langsung kemudian mahasiswa mempraktikan apa yang telah dijelaskan oleh instruktur. Mahasiswa peserta pelatihan diwajibkan untuk membawa laptop dengan koneksi jaringan yang memadai sehingga pelatihan berlangsung efektif. Instruktur akan memandu satu per satu mahasiswa untuk mengikuti petunjuka yang telah diberikan. Evaluasi program dilakukan dengan melakukan review hasil unggahan mahasiswa pada website FIPA.

\section{HASIL DAN PEMBAHASAN}

Pada sesi awal pelatihan, instruktur memberikan arahan bahwa publikasi merupakan kewajiban sebagai bentuk tridharma Perguruan Tinggi. Ketika melakukan publikasi, mahasiswa harus memperhatikan bahwa ada etika tertentu yang tidak boleh dilanggar ketika melakukan publikasi ilmiah. Etika publikasi ilmiah yang disampaikan mengacu pada COPE yang melingkupi kontribusi kepengarangan bersama, konflik kepentingan, plagiasi, Data dan reproduktifitas, hak milik intelektual dan manajemen jurnal.

Ketika materi etika kepengarangan bersama, mahasiswa diberikan pengarahan bahwa untuk menulis artikel ilmiah hasil karya skripsinya harus mencantumkan semua nama dosen pembimbing yang berkontribusi. Pada materi ini juga disampaikan bahwa mahasiswa wajib ditulis sebagai penulis pertama, jika ada tuntutan untuk menggeser nama penulis itu merupakan suatu pelanggaran etika.

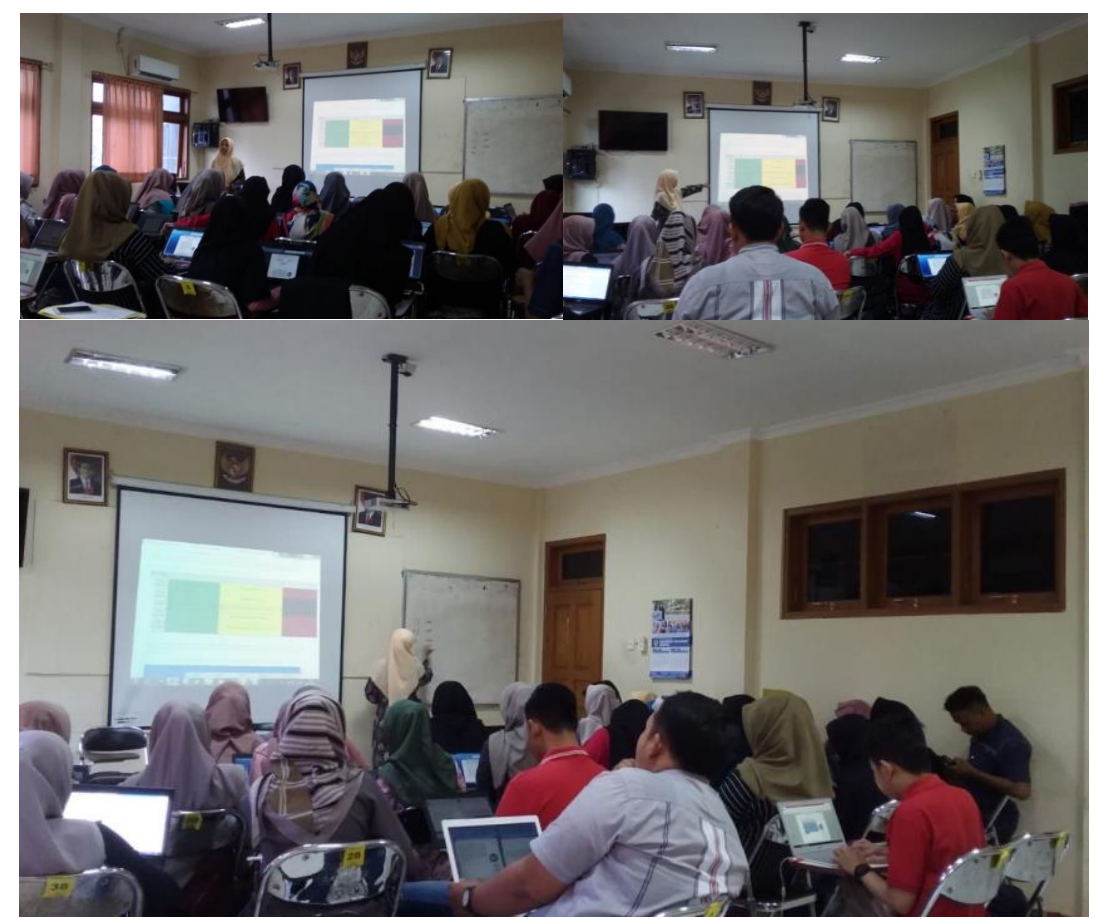

Gambar 1. Penyampaian Etika Publikasi dan Sanksi Pelanggaran

Gambar 1 merupakan penyampaian materi tentang plagiasi dilakukan dengan mengacu pada website Anjani yang telah dirilis oleh kemenristek DIKTI. Mahasiswa 
diberikan pemahaman bahwa menggunakan pernyataan orang lain tanpa melakukan citasi adalah suatu pelanggaran etika akademik. Mahasiswa diberikan pengarahan mengenai sanksi pemberian poin dan konsekuensinya yang telah ditetapkan oleh Kemenristek DIKTI ketika mereka tetap melakukan kecurangan integritas.

Materi manajemen jurnal diawali dengan pengenalan peran-peran yang ada dalam pengelolaan jurnal dinataranya pembaca (reader), penulis (author), penyunting (editor) dan mitra bestari (reviewer). Masing-masing dari peran tersebut memeiliki kepentingan yang berbeda dalam menerima informasi (Prayudi, Vijaya, \& Ekawati, 2017). Selanjutnya instruktur memberikan pengarahan bahwa untuk menerbitkan suatu artikel ilmiah dalam jurnal online memerlukan proses yang cukup panjang. Hal ini dimulai dari proses review oleh editor, reviewer, kemudian upload revision naskah oleh author sehingga perlu dibangun pemahaman ketika ada penawaran untuk publikasi dalam waktu singkat dan biaya yang sangat mahal, maka perlu diwaspadai kemungkinan jurnal predator. Mahasiswa juga diberikam pemahaman bahwa ketika sudah memutuskan untuk melakukan submisi pada suatu jurnal, maka artikel tersebut tidak boleh diproses submit ke jurnal lain, harus menunggu sampai ada keterangan ditolak, direvisi ataupun diterima pada jurnal yang pertama kali dituju.

Setelah mahasiswa memahami etika publikasi sesuai kaidah COPE, pelatihan dilanjutkan dengan demonstrasi pemanfaatan OJS. Gambar 2 mendokuemntasikan proses pemanfaatan OJS dimulai dengan pembuatan akun penulis dengan menggunakan fitur register di OJS. Instruktur memperagakan cara melakukan register dan menjelaskan satu per satu kolom yang harus diisi dalam OJS yang selanjutnya akan digunakan untuk submisi naskah. Pada intinya proses register berjalan dengan lancar, beberapa pertanyaan mahasiswa dalam sesi ini terkait dengan Orchid ID dan URL. Instruktur menanggapi pertanyaan tersebut dengan mebukakan akun Orchid ID dan Google Scholar salah satu dosen. Instruktur juga memberikan penjelasan bahwa google scholar merupakan salah satu sumber rujukan yang dapat digunakan dalam proses penulisan naskah ilmiah (Romli, 2014).

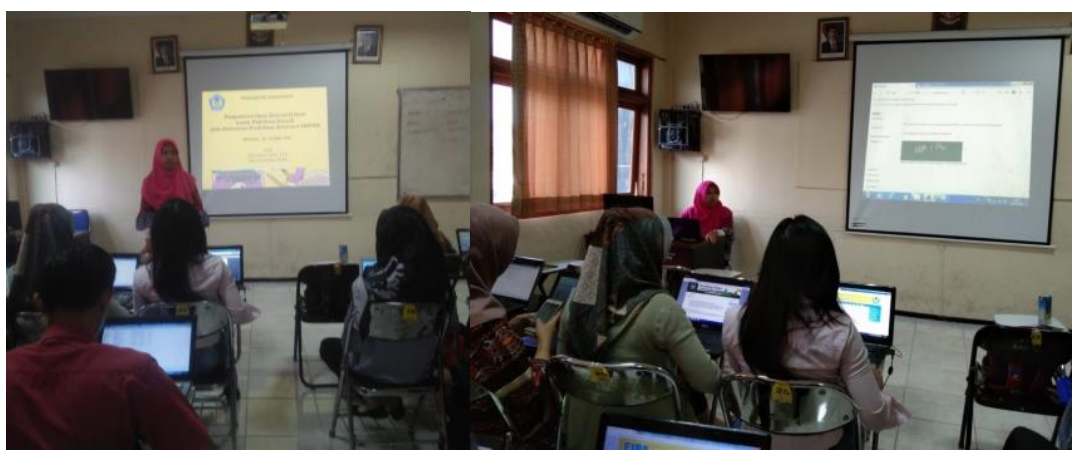

Gambar 2. Proses Registrasi di FIPA (OJS untuk Proceeding Milik Prodi)

Tahap selanjutnya adalah proses submisi naskah pada OJS. Proses submisi melingkupi lima tahap yaitu Starting the Submission, Upload Submission, Enter Metadata, Upload Supplementary Files, dan Confirmation. Pada tahap awal Starting submission tidak ada kendala yang berarti karena mahasiswa hanya diminta untuk memberikan check list pada kolom yang telah disediakan dan klik save and continue. Pada langkah kedua ketika melakukan unggah naskah, beberapa mahasiswa gagal karena kurang memperhatikan 
arahan dari instruktur. File yang diterima untuk unggah di website FIPA harus dalam bentuk word 1997-2003.

Ketika proses enter metadata, mahasiswa diminta untuk mengisikan informasi umum terkait artikel yang diunngah. Beberapa informasi yang harus diisi pada proses ini adalah nama penulis, judul artikel, abstrak, kata kunci dan daftar pustaka. Beberapa kendala yang dihadapi mahasiswa untuk mengisi informasi ini adalah tata urutan penulis yang sering terbolak baik atau nama-nama penulis yang terulang beberapa kali.

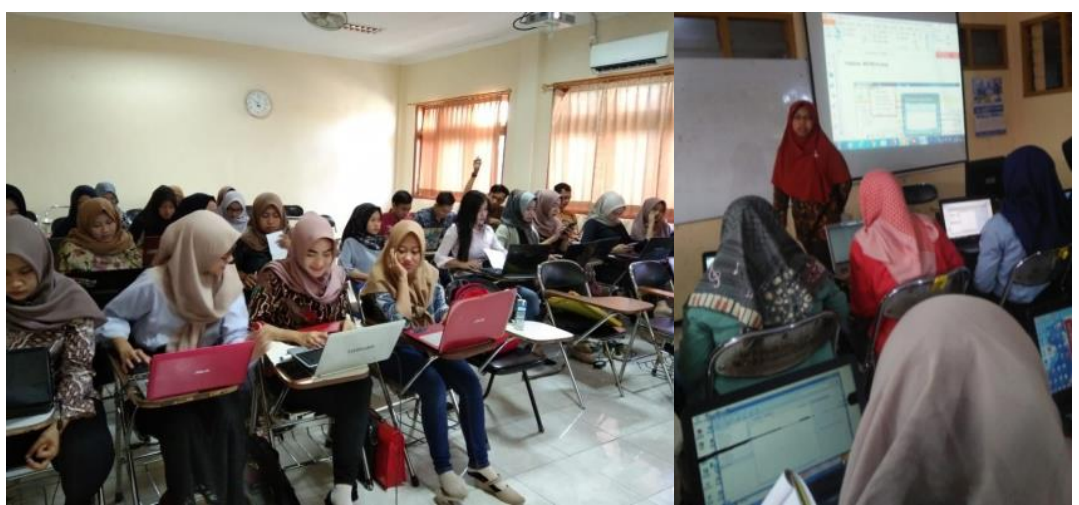

Gambar 3. Proses Unggah Dokumen dan Sesi Tanya Jawab

Gambar 3 merupakan proses upload supplementary files digunakan untuk melakukan unggah file pendukung penelitian seperti data sampel penelitian, dokumentasi penelitian, luaran uji statistic, transkip wawancara, dan dokumen lainnya. Pada tahap ini mahasiswa agak kesuliatan dalam membedakan jenis data apa yang diunggah dan memberikan keterangan file. Kendala lainnya adalah file yang terlalu besar harus dipecah dahulu sehingga sedikit menghambat proses pengunggahan dokumen.

Langkah terakhir yang dilakukan dalam proses unggah naskah adalah confirmation. Pada langkah ini penulis hanya diminta untuk konfirmasi apakah file yang diunggah sudah benar. Jika sudah dapat dipastikan bahwa semua telah terisi dengan baik dan benar maka klik finish submissions.

Tahap selanjutnya mahasiswa dibimbing untuk melakukan log out dari website FIPA dan mencoba untuk proses log in kembali. Hal ini digunakan untuk memastikan peserta pelatihan tetap mengingat username dan password masing-masing. Beberapa perserta gagal log in dan terpaksa reset password pada proses ini. Instruktur kemudian memberikan arahan untuk mengingat selalu username dan password karena itu akan digunakan secara berkelanjutan untuk memantau progress artikel yang diunggah.

Setelah proses $\log$ in dan $\log$ out secara berulang berhasil dilakukan oleh mahasiswa, selanjutnya mahasiswa dibimbing untuk melakukan unggah naskah revision melalui author version di pada menu review di OJS. Pada proses ini, semua peserta berhasil melakukan pengunggahan tanpa terkendala.

Kegiatan pelatihan diakhiri dengan memperkenalkan website sinta kepada peserta pelatihan. Mahasiswa diberikan pengarahan bahwa untuk mencari jurnal yang baik untuk publikasi karya ilmiah dapat memanfaatkan website sinta. Untuk tataran S1 diperbolehkan publikasi pada sinta peringkat berapapun sepanjang jurnal tersebut sudah terintegrasi dengan GARUDA. Instruktur menyampaikan kepada mahasiswa bahwa 
masing-masing jurnal memiliki gaya selingkung sendiri, untuk itu jika berminat untuk melakukan submisi artikel ilmiah sebaiknya pelajari telebih dahulu gaya selingkung jurnal yang dituju.

\section{SIMPULAN}

Berdasarkan pelatihan yang telah dilakukan, mahasiswa telah memahami akan pentingnya publikasi karya ilmiah mereka pada jurnal yang tergabung dalam sinta serta terintegrasi dengan portal Garuda. Mahasiswa juga telah memahami bahwa dalam proses publikasi tersebut, mereka harus mematuhi etika publikasi ilmiah yang sesuai dengan COPE. Pelatihan dan pengenalan OJS ini sangat bermanfaat bagi mahasiswa untuk melakukan publikasi karyanya secara beretika dan memenuhi standar kualitas yang diharapkan dalam jurnal.

\section{REFERENSI}

Fatmawati, E. (2013). Gerakan open access dalam mendukung komunikasi keilmuan. Visi Pustaka, 15(2), 96-106.

Irawan, D. E., Abraham, J., Multazam, M. T., Rachmi, C. N., Mulyaningsih, I., Viridi, S., ... \& Puradimaja, D. J. (2018). Era baru publikasi di Indonesia: status jurnal open access di Directory of Open Access Journal (DOAJ). Berkala Ilmu Perpustakaan dan Informasi, 14(2), 133-147. https://doi.org/10.22146/bip.32920

Kristina. (2018). Menjadi scholarly communication librarians. Pustabiblia: Journal of Library and Information Science, 2(2), 183-194.

Mauko, I. C., Setiohardjo, N. M., \& Noach, F. P. (2017). Pengembangan website unit penelitian dan pengabdian kepada masyarakat dan penerapan jurnal elektronik berbasis open source di Politeknik Negeri Kupang. Jurnal Ilmiah FLASH, 3(2), 100108.

Prayudi, M. A., Vijaya, D. P., \& Ekawati, L. P. (2017). Pengembangan sistem informasi manajemen pengelolaan dan penerbitan jurnal ilmiah jurusan akuntansi program S1. In N. Suharsono, N. M. A. Widiastini, \& E. Sujana (Eds.), Seminar Nasional TEAM (Tourism, Economics, Accounting, Management): Strengthening Economic for Global Competitiveness (pp. 589-604). Universitas Pendidikan Ganesha, Singaraja, Indonesia.

Romli, A. S. M. (2014). Jurnal online sebagai media publikasi karya tulis ilmiah. In Pedoman Penulisan Karya Tulis Ilmiah LIPI (pp. 1-5). Jakarta: LIPI.

Shiddieq, D. F., Purwanto, H., \& Santoso, A. B. (2018). Pemanfaatan open journal system pada jurnal teknologi informasi LPKIA Bandung. Jurnal LPKIA, 11(2), 40-48.

Yunus, A. M. S., Abadi, S., Bhuana, C., \& Djalal, M. R. (2018). PKM perguruan tinggi di dalam pembuatan dan manajemen open journal system (OJS). In Prosiding Seminar Hasil Pengabdian (SNP2M) Vol 1 (pp. 197-199). 